\title{
Using Contrast-Enhanced Ultrasound in Addition to Cross-Sectional Imaging for Indeterminate Renal Cysts May Lead to Overclassification in Bosniak III Category: A Case-Control Study
}

\author{
François Audenet ${ }^{a} \quad$ Jordan Sapetti $^{b}$ Christophe Delavaud ${ }^{c}$ Virginie Verkarre ${ }^{d}$ \\ Jean-Michel Correas ${ }^{c}$ Arnaud Mejean $^{a}$ Marc-Olivier Timsit ${ }^{a}$ \\ aDepartment of Urology, Hôpital Européen Georges Pompidou, AP-HP Centre, Université de Paris, Paris, France; \\ ${ }^{b}$ Department of Urology, Hôpital Cochin, AP-HP Centre, Université de Paris, Paris, France; ' ${ }^{\circ}$ Department of Adult \\ Radiology, Hôpital Necker, AP-HP Centre, Université de Paris, Paris, France; dDepartment of Pathology, Hôpital \\ Européen Georges Pompidou, AP-HP Centre, Université de Paris, Paris, France
}

\section{Keywords}

Bosniak classification - Complex renal cysts - Contrastenhanced ultrasound · Malignancy $\cdot$ Imaging modalities

\begin{abstract}
Introduction: Indeterminate renal cysts may require several imaging modalities before clinical decision. The aim of this study was to investigate the effect of the imaging modality used to characterize indeterminate renal cysts on the pathological findings after surgical resection. Methods: From our institutional database, we identified all patients surgically treated for Bosniak III renal masses between January 2008 and January 2018. All complex renal cysts were characterized with a combination of computed tomography (CT) and/ or magnetic resonance imaging (MRI), and/or contrast-enhanced ultrasound (CEUS) and discussed during a multidisciplinary tumor board. Potential association between clini$\mathrm{cal} /$ radiological characteristics and the pathological findings were investigated, using univariate and multivariate analyses. Results: Of the 52 renal cystic lesions surgically removed, with a preoperative diagnosis of Bosniak III renal cyst, 19 (37\%) were malignant and 33 (63\%) were benign. The proportion of malignant lesions decreased from $47 \%$ when the
\end{abstract}

renal cyst was characterized with cross-sectional imaging (CT and/or MRI) to 17\% when the diagnosis required CEUS in addition to cross-sectional imaging. In multivariate analysis, prior history of renal cell carcinoma was associated with a higher risk of malignancy $(p=0.016)$ and diagnosis made with CEUS was associated with a lower risk of malignancy $(p=0.040)$. Conclusion: We found that using CEUS in addition to cross-sectional imaging to characterize indeterminate renal cysts tends to redefine Bosniak III as lesions with a lower risk of malignancy and can lead to overclassification.

(c) 2021 S. Karger AG, Basel

\section{Introduction}

Renal cell carcinoma (RCC) represents $2-3 \%$ of all cancers, with the highest incidence in Western countries [1]. Over the last 2 decades, the incidence of RCC has increased by about $2 \%$, mainly due to increased incidental detection of tumors by ultrasound and computed tomography (CT) [2]. Along with solid renal tumors, there has also been an increase in the detection of cystic renal masses, of which $8-15 \%$ are complex cystic masses [3].
Correspondence to:

François Audenet, francois.audenet@aphp.fr 
Table 1. Characteristics of the population

\begin{tabular}{|c|c|}
\hline Variables & $N=52$ \\
\hline Median age at diagnosis, years [IQR] & $54.1[46.0 ; 61.7]$ \\
\hline \multicolumn{2}{|l|}{ Gender, $n(\%)$} \\
\hline Male & $28(54)$ \\
\hline Female & $24(46)$ \\
\hline \multicolumn{2}{|l|}{ Smoking status, $n(\%)$} \\
\hline Active/former & $15(33)$ \\
\hline Never & $31(67)$ \\
\hline Median BMI, kg/m² [IQR] & $25.3[22.1 ; 26.6]$ \\
\hline End-stage CKD, $n(\%)$ & $5(10)$ \\
\hline Prior history of RCC, $n(\%)$ & $7(13)$ \\
\hline Symptoms at diagnosis, $n(\%)$ & $11(21)$ \\
\hline Median size of the lesion, $\mathrm{cm}$ [IQR] & $4.5[3.0 ; 6.9]$ \\
\hline \multicolumn{2}{|l|}{$\begin{array}{l}\text { Imaging modality that allowed the } \\
\text { classification of the cyst, } n(\%)\end{array}$} \\
\hline Cross-sectional imaging & $34(65)$ \\
\hline CEUS & $18(35)$ \\
\hline \multicolumn{2}{|l|}{ Type of surgery, $n(\%)$} \\
\hline Partial nephrectomy & $43(83)$ \\
\hline Radical nephrectomy & $9(17)$ \\
\hline \multicolumn{2}{|l|}{ Pathology } \\
\hline Benign, $n(\%)$ & $33(63)$ \\
\hline Epithelial cyst & 21 \\
\hline Cystic nephroma & 11 \\
\hline Metanephric adenoma & 1 \\
\hline Malignant, $n(\%)$ & $19(37)$ \\
\hline Multilocular cystic RCC & 9 \\
\hline Clear cell RCC & 3 \\
\hline Papillary RCC & 3 \\
\hline Tubulocystic RCC & 2 \\
\hline Chromophobe RCC & 2 \\
\hline
\end{tabular}

IQR, inter-quartile range; $\mathrm{BMI}$, body-mass index; $\mathrm{CKD}$, chronic kidney disease; RCC, renal cell carcinoma; CEUS, contrast-enhanced ultrasound.

Since the introduction of the Bosniak classification for renal cysts in 1986, clinical management of such lesions has been primarily guided by radiological assessment [4]. While simple and minimally complex cysts (Bosniak I and II) do not require any treatment or surveillance, more complex cysts (Bosniak III and IV) are recommended for treatment due to a high risk of malignancy $[5,6]$.

However, the imaging characterization has improved over time and could lead to stage migration. The Bosniak classification was extended to magnetic resonance imaging (MRI) in 2004 [7] and updated in 2019 [8]. Contrastenhanced ultrasound (CEUS) is now a valuable alternative to further characterize indeterminate renal lesions $[9$, 10]. Consequently, we aimed to investigate the effect of CEUS for the characterization of indeterminate renal cysts on CT and/or MRI before surgical resection.

\section{Materials and Methods}

\section{Population of the Study}

After approval from the Ethical Committee of the French Association of Urology, a retrospective review was performed to identify patients with Bosniak III renal cyst treated surgically at our center between January 2008 and January 2018. Patients who underwent active surveillance or watchful waiting because of elder age and comorbid disease were excluded. We also excluded patients with a known hereditary syndrome or when a Bosniak III cyst was associated with a synchronous solid renal tumor. Out of 926 patients treated with radical or partial nephrectomy for renal tumors, we identified 52 patients diagnosed with a preoperative Bosniak III lesion who met our criteria for analysis. Demographic and medical characteristics were collected. All surgical specimens were reviewed by a dedicated uropathologist (V.V.) and classified according to the 2012 International Society of Urological Pathology classification [11].

\section{Diagnostic Imaging Studies}

Prior to surgery, all imaging studies were reviewed by senior radiologists specialized in renal tumors (C.D. and J.-M.C.). The lesions were characterized by a combination of enhanced CT and/ or MRI. Cysts were considered indeterminate when cross-sectional imaging was not able to distinguish between complex cysts (Bosniak III), recommended for surgical treatment, and minimally complex cysts (Bosniak IIF) that should undergo surveillance. In such cases, CEUS was ordered to better characterize the lesion and help the decision-making process. Details on imaging modalities are available in online suppl. material (for all online suppl. material, see www.karger.com/doi/10.1159/000517405).

\section{Statistical Analysis}

To test statistical significance of differences between clinical and demographic variables, we utilized $\chi^{2}$ or Fisher tests for categorical variables and Wilcoxon or Kruskal-Wallis tests for continuous variables. Predictive factors of malignancy were tested in univariate analysis, with $p$ value $<0.05$ considered to be significant. Factors with a significant $p$ value in univariate analysis were tested in multivariate analysis through a logistic regression model. Statistical analysis was performed using R v.3.4.3 (https://cran.r-project. org).

\section{Results}

Of the 52 renal cystic lesions surgically removed with a preoperative diagnosis of Bosniak III renal cyst, 19 (37\%) were malignant, and 33 (63\%) were benign. Median size of the lesion was $4.5 \mathrm{~cm}$ (range $1.5-13 \mathrm{~cm}$ ). Surgical pathological findings for the malignant lesions were: multilocular cystic RCC (9/19), clear cell RCC (3/19), papillary RCC (2 type 1 and 1 type 2), tubulocystic RCC (2/19), and chromophobe RCC (2/19). Only 3/19 malignant lesions were aggressive variants ( 2 papillary RCC and 1 clear cell RCC were International Society of Urological Pathology grade 3), while 16/19 were of low ma- 
Table 2. Comparison of the clinical characteristics between benign and malignant Bosniak III renal cysts

\begin{tabular}{|c|c|c|c|}
\hline Variables & $\begin{array}{l}\text { Benign, } \\
N=33\end{array}$ & $\begin{array}{l}\text { Malignant, } \\
N=19\end{array}$ & $p$ value \\
\hline Median age at diagnosis, year [IQR] & $56.3[47.8 ; 60.0]$ & $49.1[44.4 ; 63.1]$ & 0.740 \\
\hline \multicolumn{4}{|l|}{ Gender, $n(\%)$} \\
\hline Male & $16(48.5)$ & $12(63.2)$ & \multirow[t]{2}{*}{0.463} \\
\hline Female & $17(51.5)$ & $7(36.8)$ & \\
\hline \multicolumn{4}{|l|}{ Smoking status, $n(\%)$} \\
\hline Never & $20(69.0)$ & $11(64.7)$ & \multirow[t]{2}{*}{1.000} \\
\hline Active/former & $9(31.0)$ & $6(35.3)$ & \\
\hline Median BMI, kg/m² [IQR] & $25.4[22.5 ; 26.6]$ & $25.1[22.0 ; 26.2]$ & 0.652 \\
\hline \multicolumn{4}{|l|}{ End-stage CKD, $n(\%)$} \\
\hline No & $29(87.9)$ & $18(94.7)$ & \multirow[t]{2}{*}{0.641} \\
\hline Yes & $4(12.1)$ & $1(5.26)$ & \\
\hline \multicolumn{4}{|l|}{ Prior history of RCC, $n(\%)$} \\
\hline No & $32(97.0)$ & $13(68.4)$ & \multirow[t]{2}{*}{0.007} \\
\hline Yes & $1(3.0)$ & $6(31.6)$ & \\
\hline \multicolumn{4}{|l|}{ Symptoms at diagnosis, $n(\%)$} \\
\hline No & $25(75.8)$ & $16(84.2)$ & \multirow[t]{2}{*}{0.726} \\
\hline Yes & $8(24.2)$ & $3(15.8)$ & \\
\hline Median size of the lesion, $\mathrm{cm}$ [IQR] & $4.80[3.00 ; 7.75]$ & $3.50[2.75 ; 5.50]$ & 0.161 \\
\hline \multicolumn{4}{|c|}{ Imaging modality that allowed the classification of the cyst, $n(\%)$} \\
\hline Cross-sectional imaging & $18(54.5)$ & $16(84.2)$ & \multirow[t]{2}{*}{0.063} \\
\hline CEUS & $15(45.5)$ & $3(15.8)$ & \\
\hline
\end{tabular}

$p$ values in bold are statistically significant. IQR, inter-quartile range; BMI, body-mass index; $\mathrm{CKD}$, chronic kidney disease; RCC, renal cell carcinoma; CEUS, contrast-enhanced ultrasound.

lignant potential. The findings for the benign lesions were: epithelial cyst with or without atypical cells (21/33), cystic nephroma (11/33), and metanephric adenoma $(1 / 33)$.

The characteristics of the population are presented in Table 1. Overall, 43/52 patients were treated with partial nephrectomy (41 open and 2 robot-assisted) and 9/52 had radical nephrectomy (8 laparoscopic and 1 open). Among the patients treated with radical nephrectomy, 5 patients had end-stage CKD, and 4 patients had a prior history of ipsilateral malignant RCC treated with partial nephrectomy.

All the imaging studies were reviewed by dedicated radiologists specialized in renal tumors and discussed during a multidisciplinary tumor board including radiologists and urologists. For 20/52 patients, only 1 imaging modality was performed (16 CT and $4 \mathrm{MRI}$ ); for $20 / 52$ patients, 2 imaging modalities were performed (14 CT + MRI, 4 CT + CEUS, 2 MRI + CEUS); for 12 patients, 3 imaging modalities were performed (CT + MRI + CEUS). CEUS was used when the cyst remained indeterminate after cross-sectional imaging (CT and/or MRI). The proportion of malignant lesions decreased from $47 \%$ when

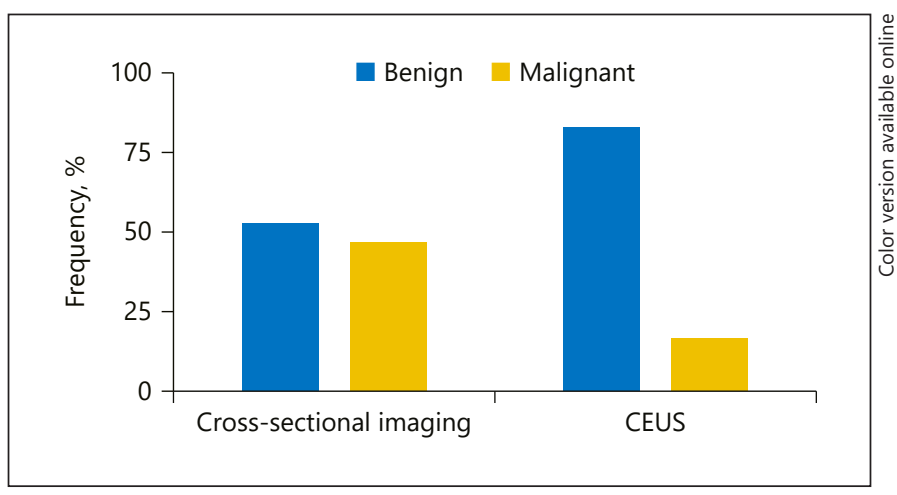

Fig. 1. Rate of benign and malignant lesions, depending on the imaging modality that allowed the classification of the renal cyst. CEUS, contrast-enhanced ultrasound.

the renal cyst was characterized with cross-sectional imaging, to $17 \%$ when diagnosis was made with CEUS (Fig. 1). Online suppl. figures show examples of CEUS cases for indeterminate lesions after CT and/or MRI.

In order to identify predictive factors of malignancy for Bosniak III renal cysts, we compared the clinical/ra- 
Table 3. Univariate and multivariate analysis of predictive factors of malignancy for Bosniak III renal cysts

\begin{tabular}{|c|c|c|c|c|}
\hline \multirow[t]{2}{*}{ Variables } & \multicolumn{2}{|l|}{ Univariate } & \multicolumn{2}{|l|}{ Multivariate } \\
\hline & OR $[95 \% \mathrm{CI}]$ & $p$ value & OR $[95 \% \mathrm{CI}]$ & $p$ value \\
\hline Age at diagnosis & $1.00[0.95 ; 1.05]$ & 0.906 & - & - \\
\hline \multicolumn{5}{|l|}{ Gender } \\
\hline Male & 1.00 (reference) & & & \\
\hline Female & $0.56[0.17 ; 1.78]$ & 0.327 & - & - \\
\hline \multicolumn{5}{|l|}{ Smoking status } \\
\hline Never & 1.00 (reference) & & & \\
\hline Active/former & $1.21[0.32 ; 4.40]$ & 0.772 & - & - \\
\hline BMI & $0.97[0.82 ; 1.15]$ & 0.737 & - & - \\
\hline \multicolumn{5}{|l|}{ End-stage CKD } \\
\hline No & 1.00 (reference) & & & \\
\hline Yes & $0.45[0.02 ; 3.55]$ & 0.482 & - & - \\
\hline \multicolumn{5}{|l|}{ Prior history of RCC } \\
\hline No & 1.00 (reference) & & & \\
\hline Yes & $12.7[1.84 ; 351]$ & 0.007 & 19.3 [2.47; 447] & 0.016 \\
\hline \multicolumn{5}{|l|}{ Symptoms at diagnosis } \\
\hline No & 1.00 (reference) & & & \\
\hline Yes & $0.61[0.11 ; 2.53]$ & 0.506 & - & - \\
\hline Size of the lesion & $0.84[0.67 ; 1.06]$ & 0.146 & - & - \\
\hline \multicolumn{5}{|c|}{ Imaging modality that allowed the classification of the cyst } \\
\hline Cross-sectional imaging & 1.00 (reference) & & & \\
\hline CEUS & $0.24[0.05 ; 0.90]$ & 0.034 & $0.18[0.02 ; 0.78]$ & 0.040 \\
\hline
\end{tabular}

$p$ values in bold are statistically significant. IQR, inter-quartile range; BMI, body-mass index; CKD, chronic kidney disease; RCC, renal cell carcinoma; CEUS, contrast-enhanced ultrasound; OR, odds ratio; CI, confidence interval.

diological characteristics between benign and malignant lesions. We found that patients with a malignant lesion after surgery had more frequently a prior history of RCC ( 32 vs. $3 \%, p=0.007)$, a smaller cyst ( 3.5 vs. $4.8 \mathrm{~cm}, p=$ 0.161 ), and were less often diagnosed with CEUS (16 vs. $84 \%, p=0.063$ ) (Table 2). In multivariate analysis, prior history of RCC was significantly associated with a higher risk of malignancy $(\mathrm{OR}=19.3,95 \%$ CI: $2.47-447, p=$ 0.016 ) and diagnosis made with CEUS was significantly associated with a lower risk of malignancy $(\mathrm{OR}=0.18$, 95\% CI: 0.02-0.78, $p=0.040$ ) (Table 3).

\section{Discussion}

In this cohort, the radio-pathological correlation for Bosniak III renal cysts found $37 \%$ of malignant lesions overall, with important differences depending on whether the lesion remain indeterminate after CT and/or MRI or not. Since 1986, the Bosniak radiographic classification has been used to guide the management of complex renal cysts, based on the risk of RCC at the time of surgery. Both
American Urological Association Guidelines and European Association of Urology Guidelines state that Bosniak cysts greater than III should be considered as RCC and be treated accordingly $[5,6]$. However, the malignancy rate of Bosniak III has the highest heterogeneity among the Bosniak classification, ranging from 31 to $100 \%[12,13]$. In a recent meta-analysis including radiological and surgical series from 1991 to 2016, the estimated prevalence of RCC for Bosniak III renal cysts was 0.51 (95\% CI: $0.44-0.58$ ) [14]. This means that $49 \%$ of these patients have been operated on for a benign lesion. In our cohort, the rate of benign lesions was even higher (63\%). This underlines the less-than-optimal grading classification within the Bosniak III category. Interestingly, the introduction of the Bosniak IIF category in 1993 to differentiate between complex cysts and minimally complex cysts [15] did not significantly affect the overall performance of the Bosniak classification; reported rates of malignancy were 0.46 before and 0.51 after the introduction of the Bosniak IIF category [14].

With an intent to better define patients at risk for malignant lesions, we performed multivariate analysis and 
found that prior history of RCC was strongly associated with the risk of malignant cyst, while the use of CEUS to characterize indeterminate cystic masses after cross-sectional imaging was associated with a lower risk of malignant lesion. Prior retrospective studies proposed several models to predict the risk of malignancy with conflicting results $[16,17]$. Renal cysts are frequently found in patients with end-stage CKD and have different prognostic significance depending on the clinical context. Native renal cysts and dialysis duration have been identified as risk factors of RCC in renal transplant recipients [18]. In our cohort, only $1 / 5$ patients with a Bosniak III renal mass and a history of end-stage CKD was found to have a malignant lesion after surgery.

The most striking finding of our study is the trend toward overclassification when CEUS was used in addition to cross-sectional imaging to characterize indeterminate renal cysts. The definition of a Bosniak III lesion is based on the identification of thickened/irregular walls or septa with measurable enhancement [8]. It was initially defined for CT and was secondarily extended to MRI [7]. We used the same definition for CEUS when it was required to characterize indeterminate cystic renal masses after crosssectional imaging [9]. Although CEUS was shown to be very concordant with CT to distinguish Bosniak II-IIF from Bosniak III-IV [19], our study is the first to highlight the role of the diagnostic strategy in the pathological outcomes. If a lesion is difficult to characterize with crosssectional imaging and requires CEUS, the probability of having a malignant lesion is much lower than a Bosniak III lesion diagnosed with CT or MRI (17 vs. $47 \%)$. CEUS provides high sensitivity in detecting microbubble signal from the vascularized wall, septa, or solid nodules of complex cystic renal masses [9]. It has been shown that CEUS had the potential to improve lesion classification and could change therapeutic options [20]. For example, it could be useful to reclassify Bosniak IIF lesions as benign cysts, allowing it to stop the follow-up. However, as CEUS can detect only a few microbubbles traveling in thin septations with a superior time and spatial resolution compared with any other imaging modalities, it may be too sensitive, with a potential to overclassify certain cases of benign cysts as Bosniak III [21]. In our study, if CEUS was not performed, the indeterminate lesions after cross-sectional imaging would have been probably classified as Bosniak IIF with follow-up imaging at 6 months.

If a significant proportion of complex cysts are benign, it is also suspected that RCC in a complex cyst may have a different natural history and may not be as aggressive as in a solid mass [22]. A risk ratio of 0.06 to die of

Malignancy of Bosniak III Cysts and Imaging Modalities clear cell RCC with a cystic architecture was reported compared to solid RCC [23]. This is consistent with the $16 / 19$ malignant lesions with low malignant potential found in our cohort. Consequently, arguing that a significant proportion of patients are overtreated, some authors investigated the role of active surveillance in cystic renal masses as an alternative to surgical treatment. The University of Toronto described its institutional experience of cystic renal masses surveillance [3]. Out of 122 patients with Bosniak III cysts, only 37 (31\%) underwent either surgical or ablative intervention, while the other patients (69\%) did not receive treatment and went under the surveillance. At last follow-up, with a median time of 65 months, all patients with surveillance were alive with no metastatic progression and none of the cysts were upgraded to Bosniak IV. These results need to be validated by prospective studies. However, surveillance for Bosniak III cysts in select patients could be considered a safe alternative in order to prevent overtreatment and limit metastatic spread.

As a retrospective single-institution series, our study has certain limitations. Radiological exams were not rereviewed for the purpose of this study and the results reflect a real-world practice. We only included patients with a Bosniak III renal cyst who were surgically treated, as surgical pathology is a strong reference for the analysis. However, this is a selection bias. The size of our population was relatively limited, although only few series in the literature included $>50$ patients with Bosniak III lesions $[13,17,24]$. Finally, although CEUS allows the characterization of renal cystic lesions as benign or malignant with at least the same accuracy as CT imaging [25], its diagnostic ability in the case of indeterminate lesions after crosssectional imaging might be poorer.

\section{Conclusion}

In our monocentric cohort of Bosniak III renal masses surgically treated, we found a malignancy rate of $37 \%$. Using CEUS in addition to cross-sectional imaging to characterize indeterminate renal cysts tends to redefine Bosniak III as lesions with a lower risk of malignancy and can lead to overclassification. As a significant proportion of these lesions are benign and when malignant and are generally of low grade/low stage, their management could evolve toward initial monitoring. These changes in management of complex renal cysts would require prospective studies to assess the benefit of such practice and the risk for delayed treatment in case of cystic RCC. 


\section{Acknowledgement}

We thank Paul Wiskirski for assistance in data collection.

\section{Statement of Ethics}

All subjects have given their written informed consent and the study protocol was approved by the Ethical Committee of the French Association of Urology (CERU-AFU).

\section{Conflict of Interest Statement}

The authors have no conflicts of interest to declare.

\section{Funding Sources}

The authors did not receive any funding.

\section{Author Contributions}

F.A., A.M., and M.-O.T. contributed to the conception of this study. F.A. and J.S. collected the data. C.D. and J.-M.C. reviewed all the radiological exams. V.V. performed the histological examination. F.A., J.S., A.M., and M.-O.T. have drafted the manuscript or substantively revised it.

\section{References}

1 Siegel RL, Miller KD, Jemal A. Cancer statistics, 2016. CA Cancer J Clin. 2020 Jan;66(1): $7-30$.

2 O’Connor SD, Pickhardt PJ, Kim DH, Oliva MR, Silverman SG. Incidental finding of renal masses at unenhanced CT: prevalence and analysis of features for guiding management. AJR Am J Roentgenol. 2011 Jul;197(1):13945.

3 Chandrasekar T, Ahmad AE, Fadaak K, Jhaveri K, Bhatt JR, Jewett MAS, et al. Natural history of complex renal cysts: clinical evidence supporting active surveillance. J Urol. 2018;199(3):633-40.

4 Bosniak MA. The current radiological approach to renal cysts. Radiology. 1986 Jan; 158(1):1-10.

5 Ljungberg B, Bensalah K, Canfield S, Dabestani S, Hofmann F, Hora M, et al. EAU guidelines on renal cell carcinoma: 2014 update. Eur Urol. 2015 May;67(5):913-24.

6 Campbell S, Uzzo RG, Allaf ME, Bass EB, Cadeddu JA, Chang A, et al. Renal mass and localized renal cancer: AUA guideline. J Urol. 2017 Sep;198(3):520-9.

7 Israel GM, Hindman N, Bosniak MA. Evaluation of cystic renal masses: comparison of $\mathrm{CT}$ and MR imaging by using the Bosniak classification system. Radiology. 2004 May; 231(2):365-71

8 Silverman SG, Pedrosa I, Ellis JH, Hindman NM, Schieda N, Smith AD, et al. Bosniak classification of cystic renal masses, version 2019: an update proposal and needs assessment. Radiology. 2019;292(2):475-88.

9 Hélénon O, Delavaud C, Dbjay J, Gregory J, Rasouli N, Correas JM. A practical approach to indeterminate and cystic renal masses. Semin Ultrasound CT MR. 2017 Feb;38(1):1027.

10 Cantisani V, Bertolotto M, Clevert DA, Correas JM, Drudi FM, Fischer T, et al. EFSUMB
2020 proposal for a contrast-enhanced ultrasound-adapted Bosniak cyst categorization: position statement. Ultraschall Med. 2020 Dec 11.

11 Srigley JR, Delahunt B, Eble JN, Egevad L, Epstein JI, Grignon D, et al. The international society of urological pathology (ISUP) Vancouver classification of renal neoplasia. Am J Surg Pathol. 2013 Oct;37(10):1469-89.

12 Sevcenco S, Spick C, Helbich TH, Heinz G, Shariat SF, Klingler HC, et al. Malignancy rates and diagnostic performance of the Bosniak classification for the diagnosis of cystic renal lesions in computed tomography: a systematic review and meta-analysis. Eur Radiol. 2017 Jun;27(6):2239-47.

13 Nouhaud FX, Bernhard JC, Bigot P, Khene ZE, Audenet F, Lang H, et al. Contemporary assessment of the correlation between Bosniak classification and histological characteristics of surgically removed atypical renal cysts (UroCCR-12 study). World J Urol. 2018 Oct;36(10):1643-9.

14 Schoots IG, Zaccai K, Hunink MG, Verhagen PCMS. Bosniak classification for complex renal cysts reevaluated: a systematic review. J Urol. 2017 Jul;198(1):12-21.

15 Bosniak MA. Problems in the radiologic diagnosis of renal parenchymal tumors. Urol Clin North Am. 1993 May;20(2):217-30.

16 Han HH, Choi KH, Oh YT, Yang SC, Han WK. Differential diagnosis of complex renal cysts based on lesion size along with the Bosniak renal cyst classification. Yonsei Med J. 2012 Jul;53(4):729-33.

17 Goenka AH, Remer EM, Smith AD, Obuchowski NA, Klink J, Campbell SC. Development of a clinical prediction model for assessment of malignancy risk in Bosniak III renal lesions. Urology. 2013 Sep;82(3):630-5.

18 Goh A, Vathsala A. Native renal cysts and dialysis duration are risk factors for renal cell carcinoma in renal transplant recipients. Am J Transplant. 2011 Jan;11(1):86-92.

19 Sanz E, Hevia V, Gómez V, Álvarez S, Fabuel JJ, Martínez L, et al. Renal complex cystic masses: usefulness of contrast-enhanced ultrasound (CEUS) in their assessment and its agreement with computed tomography. Curr Urol Rep. 2016 Dec;17(12):89.

20 Bertolotto M, Cicero C, Perrone R, Degrassi F, Cacciato F, Cova MA. Renal masses with equivocal enhancement at CT: characterization with contrast-enhanced ultrasound. AJR Am J Roentgenol. 2015 May;204(5):W557-65.

21 Xue LY, Lu Q, Huang BJ, Ma JJ, Yan LX, Wen JX, et al. Contrast-enhanced ultrasonography for evaluation of cystic renal mass: in comparison to contrast-enhanced CT and conventional ultrasound. Abdom Imaging. 2014 Dec;39(6):1274-83.

22 Winters BR, Gore JL, Holt SK, Harper JD, Lin DW, Wright JL. Cystic renal cell carcinoma carries an excellent prognosis regardless of tumor size. Urol Oncol. 2015 Dec;33(12):50513.

23 Frank I, Blute ML, Cheville JC, Lohse CM, Weaver AL, Zincke H. An outcome prediction model for patients with clear cell renal cell carcinoma treated with radical nephrectomy based on tumor stage, size, grade and necrosis: the SSIGN score. J Urol. 2002 Dec: 168(6):2395-400.

$24 \mathrm{Oh}$ TH, Seo IY. The role of Bosniak classification in malignant tumor diagnosis: a single institution experience. Investig Clin Urol. 2016 Jan;57(2): 100-5.

25 Sidhu PS, Cantisani V, Dietrich CF, Gilja OH, Saftoiu A, Bartels E, et al. The EFSUMB guidelines and recommendations for the clinical practice of contrast-enhanced ultrasound (CEUS) in non-hepatic applications: update 2017 (short version). Ultraschall Med. 2018 Apr;39(2):154-80. 